\title{
Avaliação das prescrições médicas de antibacterianos dispensadas com retenção de receita em uma farmácia no interior do Rio Grande do Sul
}

\author{
Evaluation of medical prescriptions of antibacterials dispensed with revenue retention in a \\ pharmacy from interior of Rio Grande do Sul
}

Joceleia Paz Damian ${ }^{1}$

Orcid: http://orcid.org/0000-0001-5193-0978
Thiago de Souza Claudino ${ }^{2}$

Orcid: http://orcid.org/0000-0003-1845-4935

Viviane Cecilia Kessler Nunes Deuschle ${ }^{3}$

Orcid: http://orcid.org/0000-0001-6797-0376

\section{Resumo}

Objetivo: analisar prescrições médicas de antimicrobianos dispensados em uma farmácia do interior do Estado do Rio Grande do Sul, para identificar quais os antibióticos mais dispensados. Material e Métodos: Trata-se de uma pesquisa do tipo documental, transversal e de campo, com abordagem quantitativa, desenvolvida no mês de Abril de 2019, em um estabelecimento farmacêutico. Resultados: Foram analisadas 410 prescrições médicas, em amostra obtida por conveniência. O perfil que se destaca é de mulheres com idades entre 20 à 32 anos. $\mathrm{O}$ antimicrobiano mais prescrito no período de estudo foi a Amoxicilina $(28,5 \%)$ pertencente a classe das Penicilinas, seguido de Azitromicina (13\%) pertencente à classe dos Macrolídeos. Conclusão: Conclui-se que o antibiótico mais utilizado é selecionado pelos médicos por ser um antimicrobiano eficaz em diversas situações clínicas e amplamente utilizado para problemas respiratórios que são mais comuns no período de outono e inverno, no qual foi desenvolvida a pesquisa..

Palavras-chave: anti-infecciosos; assitência farmacêutica; efeitos dos fármacos; doenças respiratórias.

\begin{abstract}
Objective: the objective of this study was to analyze medical prescriptions of antimicrobials dispensed in a farmacy within the State of Rio Grande do Sul, in order to identify the most antibiotics dispensed. Material and Methods: This is a documentary, cross-sectional and field research, with a quantitative approach, carried in April 2019, in a pharmaceutical establishment. Results: Was analyzed 410 medical prescrições, em amostra obtained by convenience. Profile that stands is of woman comities between 20 to 32 years. The antimicrobial more prescribed no study period was to Amoxicillin (28.5\%) pertaining to Penicillin classes, followed by Azithromycin (13\%) pertaining to Macrolides class. Conclusion: It can be concluded that the most commonly used antibiotic for doctors because for being an effective antimicrobial in various clinical situations and is widely used for respiratory problems that are common during autumn and winter periods, in which was carried out by research.
\end{abstract}

Keywords: anti-infective agents; pharmaceutical services; drug effects. respiratory tract diseases.

\footnotetext{
${ }^{1}$ Universidade de Cruz Alta - Unicruz. Curso de Farmácia. Rio Grande do Sul, Brasil. E-mail: joceleiadamian@hotmail.com

${ }^{2}$ Centro Universitário Metodista - IPA. Rio Grande do Sul, Brasil. E-mail: thiago_claudino@yahoo.com.br

${ }^{3}$ Universidade de Cruz Alta, Grupo de Pesquisa em Atenção Integral à Saúde. Rio Grande do Sul, Brasil. E-mail: vdeuschle@unicruz.edu.br
} 


\section{Introdução}

Os agentes antimicrobianos são fármacos usados para $\mathrm{o}$ tratamento de infecções, com capacidade de destruir um microrganismo invasor sem afetar as células do hospedeiro, consistindo em uma das classes de medicamentos mais prescritas, tanto de forma ambulatorial quanto hospitalar ${ }^{(1)}$. A seleção do antibiótico mais apropriado requer conhecimento do microrganismo em questão, a determinação de sua sensibilidade e o tipo de atividade (profilática ou curativa) e deve ser criteriosa e restrita, uma vez que interfere na microbiota do indivíduo e do ambiente $^{(2,3)}$.

Entretanto, o uso inadequado dos antimicrobianos, como o uso clínico de forma indiscriminada e excessiva, são os principais fatores que levam a resistência microbiana, surgimento de reações adversas e aumento dos custos com esses medicamentos $^{(3)}$. Entre os principais fatores que levam ao problema da resistência estão a escolha inadequada do medicamento, incluindo a posologia e via de administração, tempo de uso insuficiente e intervalos incorretos e falta de diagnóstico definido ${ }^{(4)}$. Além disso, a falta de adesão à terapia medicamentosa e a utilização de sobras de medicamentos de outros tratamentos têm contribuído com o desenvolvimento de resistência ${ }^{(5)}$.

Do ponto de vista farmacológico, a resistência microbiana aos antibióticos ocorre, por mecanismos que incluem a indução de mutação no DNA nativo ou introdução de um DNA estranho (genes de resistência) que podem ser transferidos entre gêneros ou espécies diferentes de bactérias Existem quatro mecanismos determinantes para a alta taxa de resistência aos antimicrobianos: modificação ou destruição enzimática, redução da permeabilidade celular, alterações em moléculas alvo dos antimicrobianos e produção de moléculas alvo alternativas ${ }^{(5,6)}$.

A dispensação, assim como a prescrição, envolve questões de cunho técnico, legal e clínico, resultando em um documento legal pelo qual se responsabilizam tanto quem prescreve quanto quem dispensa o medicamento, ambos estando sujeitos às ações de vigilância sanitária e à legislação de controle $^{(7,8)}$.

Com o objetivo de controlar a dispensação e comercialização dos antimicrobianos e promover o seu uso de forma racional, a Agência Nacional de Vigilância Sanitária (ANVISA) publicou a RDC 44/2010, que foi logo revogada pela RDC 20/2011. Essa resolução foi estabelecida de forma a proporcionar aos pacientes, medicamentos de qualidade, em doses adequadas e por tempo definido. Esta legislação prevê que os antimicrobianos sejam dispensados mediante receita de controle especial quando apresentadas de forma legível, por profissionais habilitados e contendo informações como: nome do medicamento ou substância, dosagem ou concentração, forma farmacêutica, quantidade (por extenso), posologia, entre outras ${ }^{(9)}$.

Desta forma, a dispensação de antimicrobianos em farmácias, passou a ser uma atividade privativa do farmacêutico e compete a este, não somente a entrega do medicamento, mas também a orientação sobre o uso correto e racional para garantir a adequada eficácia, além de evitar possíveis reações adversas e interações medicamentosas. $\mathrm{O}$ profissional farmacêutico apresenta fundamental importância para demonstrar ao paciente a importância do tratamento correto, a não interrupção do mesmo, a obediência aos intervalos e, garantir a adesão à terapia medicamentosa $^{(10,11)}$.

Diante deste contexto e, tendo em vista que a prescrição de antibióticos aumenta no início do outono devido ao aumento de doenças respiratórias que 
necessitam de tais medicamentos, o objetivo deste estudo é analisar prescrições médicas de antimicrobianos dispensadas com retenção de receita, para identificar quais antibióticos foram mais dispensados no mês de abril, e suas respectivas classes, em um município do interior do Rio Grande do sul..

\section{Materiais e Métodos}

\section{Amostra e tipo de estudo}

Trata-se de uma pesquisa do tipo observacional, transversal, com abordagem quantitativa, desenvolvida no mês de Abril de 2019, em um estabelecimento farmacêutico comercial de Tupanciretã, com amostra obtida por conveniência.

Este trabalho obteve aprovação do Comitê de Ética em Pesquisa por meio do parecer consubstanciado número 2.771.556.

\section{Delineamento da pesquisa}

As informações foram coletadas do banco de dados da farmácia, com o suporte de dados computadorizados pelo programa de gerenciamento para obtenção do perfil dos usuários e das prescrições médicas retidas na farmácia. $\mathrm{O}$ instrumento de pesquisa foi uma ficha de coleta de dados de elaboração própria em que constavam as seguintes questões: gênero, idade e antibiótico adquirido. Os resultados obtidos foram expressos em porcentagem..

\section{Critérios de Inclusão e Exclusão}

Foram incluídas as prescrições contendo antimicrobianos e excluídas aquelas que continham outros medicamentos ou que estavam fora do período de estudo

\section{Procedimentos}

Os resultados foram tabulados de acordo com a denominação dos medicamentos e posteriormente foram agrupados por classe terapêutica. Os dados foram analisados utilizando o software Microsoft Office 2013- Excel. Para a análise foi utilizada frequência relativa e absoluta e empregou-se estatística descritiva.

\section{Resultados}

Foram analisados os dados de 410 prescrições médicas contendo antimicrobianos. O perfil dos pacientes e sua distribuição por sexo está demonstrado na Tabela 1. Em uma primeira abordagem, foi possível identificar os medicamentos mais prescritos (Tabela 1), e as classes às quais pertencem (Figura 1).

Entre os medicamentos identificados, 366 foram prescritos na forma farmacêutica de comprimidos e 44 na forma de injetáveis.

Todas as receitas estavam devidamente preenchidas, seguindo as exigências da RDC n ${ }^{\circ}$ 20/2011, tais como: escrita legível; sem rasuras; identificação do paciente; nome do medicamento ou da substância prescrita sob a forma de Denominação Comum Brasileira (DCB), dose ou concentração, forma farmacêutica, posologia e quantidade; identificação do emitente, nome do profissional com sua inscrição no Conselho Regional e data da emissão.

Tabela 1. Distribuição das prescrições por sexo.

\begin{tabular}{lll}
\hline Sexo & $\begin{array}{l}\text { Número de } \\
\text { prescrições }\end{array}$ & Idade \\
\hline Feminino & 240 & 20 a 32 anos \\
Masculino & 170 & 18 a 35 anos \\
\hline
\end{tabular}

Fonte: autores. 


\section{Discussão}

As doenças respiratórias estão entre as causas mais frequentes da busca por atendimento médico, o que acaba levando ao uso de antibióticos ${ }^{(12)}$. Entretanto, nem sempre é possível aguardar a identificação do agente etiológico e seu antibiograma, devido ao quadro clínico do paciente que pode ser grave, colocando em risco a vida dele com a espera. Com base nessa premissa, a escolha do melhor antibiótico a ser utilizado está relacionada com a presunção do sítio infeccioso, da flora microbiana predominante no local de origem, dos prováveis agentes etiológicos, de resistência dos microrganismos aos antibióticos e do perfil de sensibilidade dos $\operatorname{mesmos}^{(13)}$.

Em nosso estudo, ao analisar as prescrições, todas as receitas estavam devidamente preenchidas, seguindo as exigências da $\operatorname{RDC~n}^{\circ}$ 20/2011, tais como: escrita legível; sem rasuras; identificação do paciente; nome do medicamento ou da substância prescrita sob a forma de Denominação Comum Brasileira (DCB), dose ou concentração, forma farmacêutica, posologia e quantidade; identificação do emitente, nome do profissional com sua inscrição no resppectivo Conselho Regional e data da emissão ${ }^{(9)}$. Já uma pesquisa realizada com prescrições médicas em uma farmácia comunitária no município de Caucaia - $\mathrm{CE}$, em que foram analisadas 100 prescrições, verificou-se que a maioria continham itens ilegíveis ou não continham dados referentes a posologia e faltando os dados completos do prescritor ${ }^{(14)}$.

Os resultados desse estudo demonstram que a faixa etária dos pacientes constante no banco de dados da farmácia variou de 20 a 32 anos. Esses dados corroboram com os obtidos em uma pesquisa semelhante em uma farmácia comunitária de Caucai - CE, em que a faixa etária predominante foi de 20 a 39 $\operatorname{anos}^{(14)}$.
Constatou-se que o sexo feminino foi mais prevalente em relação ao masculino, semelhantes aos dados obtidos em uma pesquisa realizada na farmácia pública de Carmo do Cajuru - MG, em que foi verificado que o gênero feminino foi o que mais utilizou os medicamentos ${ }^{(15)}$. A literatura relata que, no geral, os homens padecem mais de condições crônicas e severas de saúde do que a mulher e, observa-se que a presença de homens nos serviços de atenção primária a saúde é menor do que as mulheres, justificando a maior procura das mulheres por atendimento e tratamento médico ${ }^{(16)}$.

Em relação à forma farmacêutica, os comprimidos foram os mais prescritos, ou seja, das 410 prescrições analisadas, 366 eram nessa apresentação, o que corresponde a $89 \%$. Gonçalves et al. ${ }^{(14)}$, em seu estudo, também encontrou a frequência de $68 \%$ de comprimidos entre os antimicrobianos mais prescritos. $\mathrm{O}$ prescritor sempre deve escolher a forma farmacêutica mais conveniente e adequada às características do paciente $\mathrm{e}$, as formas sólidas, principalmente na apresentação de comprimidos possuem como vantagem um maior conforto na administração.

Somente $11 \%$ dos medicamentos prescritos eram injetáveis. Segundo Nacimento e Magalhães ${ }^{(17)}$, o uso de medicamentos pela via parenteral deve ser prescrita com cautela, uma vez que é uma das causas de não adesão à terapia e maior risco de ocorrência de reações adversas.

O antibiótico Amoxicilina, do grupo das Penicilinas, foi o medicamento mais prescrito. $\mathrm{O}$ advento dela assinalou várias possibilidades para o tratamento de doenças infecciosas em todo o mundo, passando a representar uma opção terapêutica na prevenção e tratamento de diferentes processos infecciosos e de suas complicações $^{(18)}$. Em uma pesquisa realizada no município de Erechim-RS, foi demonstrado que a Amoxicilina também foi $\mathrm{o}$ antimicrobiano mais prescrito no período do estudo ${ }^{(19)}$. 
Em relação aos casos que necessitam de tratamento com antibióticos, o mesmo deve ser escolhido de acordo com a cobertura sobre as bactérias mais comumente envolvidas na infecção. Com isso, a Amoxicilina demonstra ter esse perfil e é recomendada para os casos menos complicados, associadas ou não a inibidores das beta-lactamases, como o Clavulanato de Potássio. Entretanto, essa associação não é uma primeira opção e deve ser usada apenas em casos de comorbidades agravantes ou em suspeitas ou confirmação de casos de resistência bacteriana $^{(20)}$. Em nosso estudo, isso é evidenciado pelas prescrições dessa associação que correspondem a 10,5\% enquanto da Amoxicilina individual corresponde a 18\%. Mas em muitos lugares a Amoxicilina não está sendo recomendada como terapêutica de primeira linha, somente em algumas regiões em que é usada de acordo com o padrão de resistência evidenciado. Também, dados apontam uma maior suscetibilidade microbiana (84,2 \%), quando associada ao Clavulanato de Potássio.

Tabela 2. Antimicrobianos mais utilizados durante a pesquisa e suas respectivas classes.

\begin{tabular}{cccc}
\hline Classe de Antibiótico & Antimicrobianos & $\begin{array}{c}\text { Número de } \\
\text { prescrições }\end{array}$ & $\%$ \\
\hline Penicilinas & Amoxicilina (500 e 875 mg) & 72 & 18 \\
& Amoxicilina+Clavulanato 875mg & 42 & 10,5 \\
Macrolídeos & Azitromicina 500mg & 70 & 17,5 \\
Fluorquinolonas & Levofloxacino (500 e 750 mg) & 65 & 16 \\
Cefalosporinas & Cefalexina 500mg & 27 & 7 \\
& Ceftriaxona 1 g injetável & 27 & 7 \\
& Ceftriaxona 500 mg injetável & 17 & 4 \\
Quinolonas & Ciprofloxacino 500mg & 25 & 6 \\
& Norfloxacino 400mg & 20 & 5 \\
Lincosamidas & Clindamicina 300mg & 25 & 6 \\
Tetraciclinas & Tetraciclina 500mg & 20 & 5 \\
\hline
\end{tabular}

Fonte: Autores.

Sabe-se ainda, que os antibióticos devem ser prescritos com critérios, pois o uso desnecessário ou prolongado é um dos principais fatores relacionados à resistência dos microrganismos. As estratégias que são usadas para o uso racional de antibióticos, são baseadas na prevenção e controle das infecções, de forma a verificar a susceptibilidade dos microrganismos. Contudo, estudos demostraram que nem sempre a prescrição e os resultados clínicos estão de acordo com o antibiograma e, nem sempre esse teste é solicitado, como se observa no estudo de Tavares e Sá (2014) ${ }^{(21)}$. Esse estudo avaliou 104 episódios de infeção do trato urinário (ITU), em que foram solicitadas 46 uroculturas (que apresentaram resultados positivos), mas somente 43 antibiogramas, ou seja, não é uma estratégia usada na prática clínica. Ainda, em seis antibiogramas, o microrganismo era resistente ao antibiótico prescrito.

Conforme os resultados desta pesquisa, a Azitromicina, pertencente a classe dos Macrolídeos, aparece em segundo lugar como antimicrobiano mais dispensado. Esse medicamento é utilizado para o tratamento de infecções de tecidos moles e respiratórios causadas por bactérias Gram-positivas. A Azitromicina apresenta inúmeras vantagens, como seu amplo espectro de ação, sua rápida difusão tecidual e sua meia-vida biológica elevada. Esta pesquisa obteve resultados semelhante à um estudo que foi realizado no município de Bacabal-MA, em que foram analisadas 
124 prescrições médicas e o antimicrobiano mais prescrito foi a Azitromicina, representando $22 \%$ do total $^{(22)}$.

Analisando as classes de antibióticos, o que inclui o somatório dos medicamentos representantes de cada classe, observa-se que as Penicilinas são a classe mais prescrita, seguida das Cefalosporinas, Macrolídeos e Fluorquinolonas. Gonçalves et al. ${ }^{(14)}$, verificaram que as classes mais prescritas foram as Quinolonas, Penicilinas e Macrolídeos. Contudo, os autores realizaram sua pesquisa no mês de Fevereiro de 2016, o que pode estar relacionado com a diferença entre as classes mais dispensadas.

A nível nacional, todos os decisores políticos, com o apoio do Ministérios da Saúde, devem implementar planos nacionais para prevenção e gestão da resistência aos antibióticos, promovendo ações preventivas a fim de minimizar o uso deles incentivando novas pesquisas para o desenvolvimento de novos fármacos ${ }^{17}$. Alguns dados sugerem que o uso de antibióticos tem reduzido em muitos países na última década, decorrente do maior controle estabelecido pelas agências regulamentadoras em saúde ${ }^{(23)}$.

Ainda, no âmbito da atenção farmacêutica é de suma importância que os farmacêuticos não apenas dispensem as prescrições, mas também orientem os pacientes quanto à importância do seu uso adequado. Nicolini et al. ${ }^{(4)}$ destaca em seu estudo que a antibioticoterapia pode ficar comprometida por falta do entendimento do paciente. Muitos prescritores não informam sobre os diagnósticos, medicamentos e posologia prescritos, possíveis reações adversas e, principalmente, muitas receitas ainda são ilegíveis. Neste sentido, o farmacêutico é o profissional habilitado que pode contribuir para uma maior adesão à terapia medicamentosa e evitar reações adversas e resistência microbiana decorrente do uso inadequado dos medicamentos. Orientar, ainda, sobre a não interrupção do tratamento após alívio dos sintomas e sobre a não utilização de sobras de antibióticos de tratamentos anteriores.

Além disso, pode orientar quanto ao uso de medicamentos de venda livre e os riscos da automedicação e das possíveis interações medicamentosas, colaborando substancialmente para o uso racional de antimicrobianos, por meio da atenção farmacêutica. Sua função social vai além dos conhecimentos técnicos, imprescindíveis para o bem-estar e qualidade de vida da população.

\section{Conclusão}

Diante do exposto, pode-se observar que a Amoxicilina foi $o$ antibiótico mais utilizado no período em estudo, selecionado por ser eficaz em várias situações clínicas ou por considerar as características dos patógenos prevalentes em determinada época do ano. Observa-se que com a regulamentação da prescrição dos antimicrobianos, houve um maior controle da aquisição dos mesmos. Contudo, alguns pacientes podem fazer o uso incorreto a partir de sobras de outros tratamentos. Nesse sentido, a atuação do profissional farmacêutico, por meio da atenção farmacêutica em todos os âmbitos da saúde, se faz cada vez mais necessária para promover o uso racional dos antimicrobianos de forma efetiva e garantir a sua utilização de forma adequada. 


\section{Referências}

1. Paz EF, Stefanon EBC. Avaliação da dispensação de antimicrobianos em uma farmácia hospitalar da Região Central do RS. Infarma. 2010;22(1/4):55-57.

2. Oliveira WL, Branco AB, Avaliação da antibioticoterapia em pacientes internados no Hospital Regional do Guará - DF. Comunicação em Ciências da Saúde. 2007;18(2): 107-114.

3. Fernandes IQ, Sousa HF, Brito MAM, Tavares SN, Matos VC, Souza MOB. Impacto farmacoeconômico da racionalização do uso de antimicrobianos em Unidades de Terapia Intensiva. Revista Brasileira de Farmácia Hospitalar e Serviços de Saúde. 2012;3(4):1014.

4. Nicolini P, Nascimento JWL, Greco KV, Menezes FG. Fatores relacionados à prescrição médica de antibióticos em farmácia pública da região Oeste da cidade de São Paulo. Revista Ciência \& Saúde Coletiva. 2008;13(supl.):689-696.

5. Loureiro RJ, Roque F, Rodrigues AT, Herdeiro MT, Ramalheira E. O uso de antibióticos e as resistências bacterianas: breves notas sobre a sua evolução. Revista Portuguesa de Saúde Pública. 2016;34(1):77-84.

6. Roque F, Soares S, Breitenfeld L, Lopez Duran A, Figueiras A, Herdeiro MT. Attitudes of community pharmacists to antibiotic dispensing andmicrobial resistance: A qualitativ estudy in Portugal. Int J Clin Pharm.2013;35:417-24.

7. Junior AG. Análise das prescrições de antimicrobianos dispensados em uma drogaria da cidade de Colider-MT. FACIDER Revista Científica. 2015;(8):1-15.

8. Leite SN, Bernardo, NLMC, Álvares J, Junior AAG, Costa EA, Acurcio FA, et al. Serviço de dispensação de medicamentos na atenção básica no SUS. Revista de Saúde Pública. 2017;51(supl. 2:11S):1S-10S.

9. BRASIL. Ministério da Saúde. Agência Nacional de Vigilância Sanitária (ANVISA). RDC 20 de 9 de Maio de 2011. Dispõe sobre o controle de medicamentos à base de substâncias classificadas como antimicrobianos, de uso sob prescrição, isoladas ou em associação. Brasília - DF, 2011.

10. Guedes RF, Guedes RF, Guedes HHS. O papel educativo do farmacêutico frente ao desafio da implantação da RDC 20/2011: da automedicação ao consumo consciente de antimicrobianos. Revista Eletrônica Gestão e Saúde. 2014;5(2):436-458.

11. Ladeira R, Moraes W, Oliveira C. Perfil de dispensação de antimicrobianos antes e depois da promulgação da RDC 44/2010. Revista Acta Brasiliensia. 2017;8(2):47-56.

12. Paganotti AM, Reis RA, Crozatti MTL, Silva ATA, Fegadolli C. Prescrição de antibióticos a crianças atendidas no inverno em Unidade de Saúde de município paulista. Revista Brasileira de Ciências Farmacêuticas Básica e Aplicada. 2013;34(3):441-447.

13. Bisson MP. Farmácia Clínica e atenção farmacêutica. 2ed. São Paulo: Manole, 2007.

14. Gonçalves M, Ribeiro J, Silva J, Francelino M. Avaliação das receitas de antimicrobianos dispensados em uma farmácia comunitária no município de Caucaia - Ceará. Boletim Informativo Geum. 2017;8(1):15-22.

15. Costa M. Análise das prescrições de antimicrobianos: farmácia pública da prefeitura de Carmo do Cajuru. Revista Saúde e Desenvolvimento. 2016;9(5):73-84.

16. Gomes R, Nascimento EF, Araujo FC. Porque homens buscam menos os serviços de saúde do que as mulheres? As explicações de homens com baixa escolaridade e homens com ensino superior. Saúde Pública. 2017;23(3):565-574.

17. Nascimento OS, Magalhães IRS. Análise da prescrição de antimicrobianos dispensados em uma rede de drogarias da região Norte do Brasil. Revista Brasileira de Farmácia. 2013;94(3):211-218. 
18. Franco J, Mendes R, Cabral F. O papel do farmacêutico frente à resistência bacteriana ocasionada pelo uso irracional de antimicrobianos. Revista Científica. 2016:1(72):1-17.

19. Valentini MH, Silva AC, Roginski AC, Chicota LC, Grazziotin NA, Diefenthaeler HS. Análise da qualidade de prescrições de antimicrobianos comercializados em uma drogaria da Região Norte do Rio Grande do Sul.HU Revista. 2017;43(1):19-24.

20. Piltcher OB, Kosugi EM, Sakano E, Mion O, Testa JRG, Romano FR, et al. How to avoid the inappropriate use of antibiotics inupper respiratory tract infections?A position statement from na expert panel. Brazilian Jorunal of Otorhinolaryngology. 2018;84(3):265-279.

21. Tavares IVB, Sá AB. Perfil de prescrição de antimicrobianos para infecções do trato urinário nos cuidados de saúde primários. Revista Portuguesa de Medicina Geral e Familiar. 2014;30(2 ):85-100.

22. Firmo W, Paredes A, Cunha C, Torres AG, Buccini DF. Análise das prescrições médicas de psicotrópicos de uma farmácia comercial no município de Bacabal, Maranhão. Journal of Management \& Primary Health Care. 2013;4(1):10-18.

23. Brito MA, Cordeiro BC. Necessidade de novos antibióticos. Jornal Brasileiro de Patologia e Medicina Laboratorial. 2012;48(4):247-249.

\section{Como citar este artigo:}

Damian JP, Claudino TS, Deuschle VCKN. Avaliação das prescrições médicas de antibacterianos dispensadas com retenção de receita em uma farmácia no interior do Rio Grande do Sul. Rev. Aten. Saúde. 2021; 19(68): 193-200. 